\title{
Autoinjector preference among patients with multiple sclerosis: results from a national survey
}

This article was published in the following Dove Press journal:

Patient Preference and Adherence

3 August 2017

Number of times this article has been viewed

\section{Limmroth' \\ J Reischl2 \\ B Mann ${ }^{3}$ \\ $X$ Morosov $^{2}$ \\ A Kokoschka ${ }^{2}$ \\ I Weller ${ }^{2}$ \\ T Schreiner ${ }^{2}$}

'Clinic for Neurology and Palliative Medicine, Municipal Hospital KölnMerheim, Cologne, ${ }^{2}$ Bayer Vital GmbH, Leverkusen, ${ }^{3}$ IFAK Institute $\mathrm{GmbH}$ \& Co. KG, Taunusstein, Germany
Correspondence: T Schreiner

Bayer Vital GmbH, Kaiser-Wilhelm-Allee

70, 5 I373 Leverkusen, Germany

Tel +49 2I4305 I049

Fax +492143051056

Email thomas.schreiner@bayer.com
Purpose: Autoinjectors are well-established in supporting multiple sclerosis (MS) therapy. This market survey was aimed at investigating patients' rating of three devices for subcutaneous interferon beta formulations: the electronic autoinjectors Betaconnect ${ }^{\mathbb{B}}$ and RebiSmart ${ }^{\mathrm{TM}}$ as well as the mechanical ExtaviPro ${ }^{\mathrm{TM}}$ device.

Patients and methods: Organization and conduction of structured face-to-face interviews in five German cities were managed through an independent external market research company. After questionnaire validation $(n=15), 85$ participants currently either using the Betaconnect $(n=39)$, the RebiSmart $(n=36)$ or the ExtaviPro injector $(n=10)$ were asked 22 questions in the same order. First, patients named their current device in use, watched the corresponding instruction video, and were queried about their device. Second, patients were asked about their opinion of an ideal autoinjector. Third, instruction videos for the two non-used devices were presented and participants could dummy-inject into a pillow. Last, patients evaluated device features and indicated their preferred autoinjector.

Results: Before having been presented the two other autoinjectors not in use, evaluation of patients' satisfaction with their own device revealed that $82 \%$ of the Betaconnect users, $67 \%$ of the RebiSmart and $60 \%$ of the ExtaviPro users were highly satisfied. All patients desired some improvement of their own device particularly concerning optimization of size and handling. Subsequent to testing and watching instruction videos of all devices, the Betaconnect received the best rating regarding different functions. Finally, participants indicated their preferred autoinjector, provided their own medication was suitable for all three devices: $56.5 \%$ of the participants $(n=48 / 85)$ chose the Betaconnect, 36.5\% the RebiSmart $(n=31 / 85)$, and $5 \%$ the ExtaviPro device $(\mathrm{n}=4 / 85) ; 2 \%$ did not answer $(\mathrm{n}=2 / 85)$.

Conclusion: In this survey, the Betaconnect device was the preferred autoinjector and may currently best meet patients' needs. As it was closest to participants' opinion of an ideal device, the Betaconnect might contribute to treatment adherence. Our results need to be confirmed in further studies.

Keywords: adherence, multiple sclerosis, immunomodulatory therapy, electronic autoinjector, market survey

\section{Introduction}

Injectable subcutaneous (s.c.) therapies are well-established first-line multiple sclerosis (MS) treatments and the benefits of autoinjectors in the application of these treatments are widely accepted. As for other therapies, adherence may influence treatment success. ${ }^{1,2}$ Besides efficacy of a therapeutic strategy, major factors for patient adherence to the prescribed medication and satisfaction with self-administered injections are ease of application as well as acceptable side-effect profiles. ${ }^{2}$ In addition, MS worsening might induce deteriorations in cognitive and fine-motor skills which interfere with manual injection and subsequently with adherence. .,3 $^{2,}$ 
Interferon beta preparations have been available for decades and extensively tested for efficacy and safety. Over time, these agents underwent improvements with respect to injection tolerability as well as handling (e.g., titration at therapy initiation). ${ }^{2,4}$ The invention of injection devices reduced the need for manual injection ${ }^{5-10}$ and its use significantly reduced the occurrence of injection site reactions. ${ }^{11}$ Moreover, their use was found to be a predictor of adherence. ${ }^{12}$

Autoinjection devices simplify MS therapy and often provide additional features to improve patient comfort and adherence. These features comprise reminder functions as forgetfulness is a major obstacle for self-administered therapies ${ }^{2,3,13}$ - simplicity, adjustability of injection speed and depth, optical and acoustic signaling at the beginning/ end of the injection process, hidden needle, low-force safety release to ensure the device is positioned on the skin correctly at the time of injection, and an LED-display for visualization of the injection progress. ${ }^{6,8,10,14,15}$

Several autoinjection devices for application of immunomodulatory drugs are currently available in the MS market and characterized by different handling, features, and design. Among these, the Betaconnect ${ }^{\circledR}$ (Medicom Innovation Partner A/S, Struer, Denmark) and the RebiSmart ${ }^{\mathrm{TM}}$ (Ares Trading SA, Coinsins, Switzerland) are the only electronic devices in the MS therapy field, all others are mechanical devices. ${ }^{8,14}$ Recently in a survey of US patients, the electronic Betaconnect autoinjector has been rated higher than mechanical devices. ${ }^{15}$

In this market survey, the purpose was to investigate patients' evaluation of autoinjectors typically used for the application of s.c. interferon beta formulations: the Betaconnect and the RebiSmart electronic autoinjectors as well as the ExtaviPro $^{\mathrm{TM}}$ (Owen Mumford Ltd., Oxford, UK) mechanical autoinjection device.

\section{Material and methods Participants}

This market survey was conducted with $100 \mathrm{MS}$ patients from five German cities (Berlin, Frankfurt, Hamburg, Cologne, and Munich) between February and April 2016. The participants were selected via a screening questionnaire containing questions about age, gender, MS diagnosis, medication, and autoinjector use. All participants signed a written informed consent form for this survey. The initial 15 participants served for validation of the questionnaire. After the validation, video instructions were presented to the patients to ensure that every patient got the same information about each device. The main analysis group of patients $(n=85)$ was included in data analysis. Of these participants, 39 currently used the Betaconnect autoinjector, 36 the RebiSmart, and 10 the ExtaviPro device for application of their s.c. interferon beta therapy.

\section{Interviews}

Structured face-to-face interviews (40-45 minutes per interview) were organized and conducted through an independent external market research company (IFAK Institut GmbH \& CoKG, Taunusstein, Germany) according to international quality standards (e.g., ISO 20252:2012). Participants did not receive any information about the survey initiator and sponsor. Subsequent to the interviews, all participants were compensated for their time with an allowance. The IFAK Institut $\mathrm{GmbH} \& \mathrm{CoKG}$ operates in accordance with all requested Market Research guidelines and follows the Freiwillige Selbstkontrolle für die Arzneimittelindustrie e.V. [Voluntary Self-regulation for the Pharmaceutical Industry] (FSA)-Codex. In case any notifiable adverse events (AEs) are reported of a drug, product or medicine during one or more interviews, IFAK Institut $\mathrm{GmbH} \& \mathrm{CoKG}$ obligates oneself to document these AEs following the client's standard and forward all information to the client's safety drug department.

\section{Questionnaire}

The questionnaire was developed in close collaboration with Bayer Vital GmbH, Leverkusen, Germany, this information was not communicated to the participants. Questionnaire validation for comprehensibility was conducted with a subgroup of participants $(n=15)$. Data from the validation group were collected in the same way and used for comparisons with the main group $(n=85)$. These data were not included in overall data analysis.

All patients were asked 22 questions in the same order. Depending on the question, answers were given openly, by marking or via a rating scale (1-10, with 10 as best rating). First, participants indicated their autoinjector currently in use, and watched an instruction video - except for the validation group ( $n=15)$ where the interviewer presented the patients' own devices to them instead of video instructions. Then patients answered questions about their satisfaction with the device in use. Second, they were asked for their view of an ideal autoinjector for MS therapy. Third, participants watched instruction videos for the two devices currently not in use (except for the validation group $[n=15]$ where the interviewer presented the two devices currently not in use to the patients instead of video instructions) and had the opportunity to dummy-inject into a pillow. Finally, the patients were asked to compare the devices as well as their functions and to determine the preferred autoinjector, provided their current medication was suitable for all three devices (Figure 1, Table S1). 


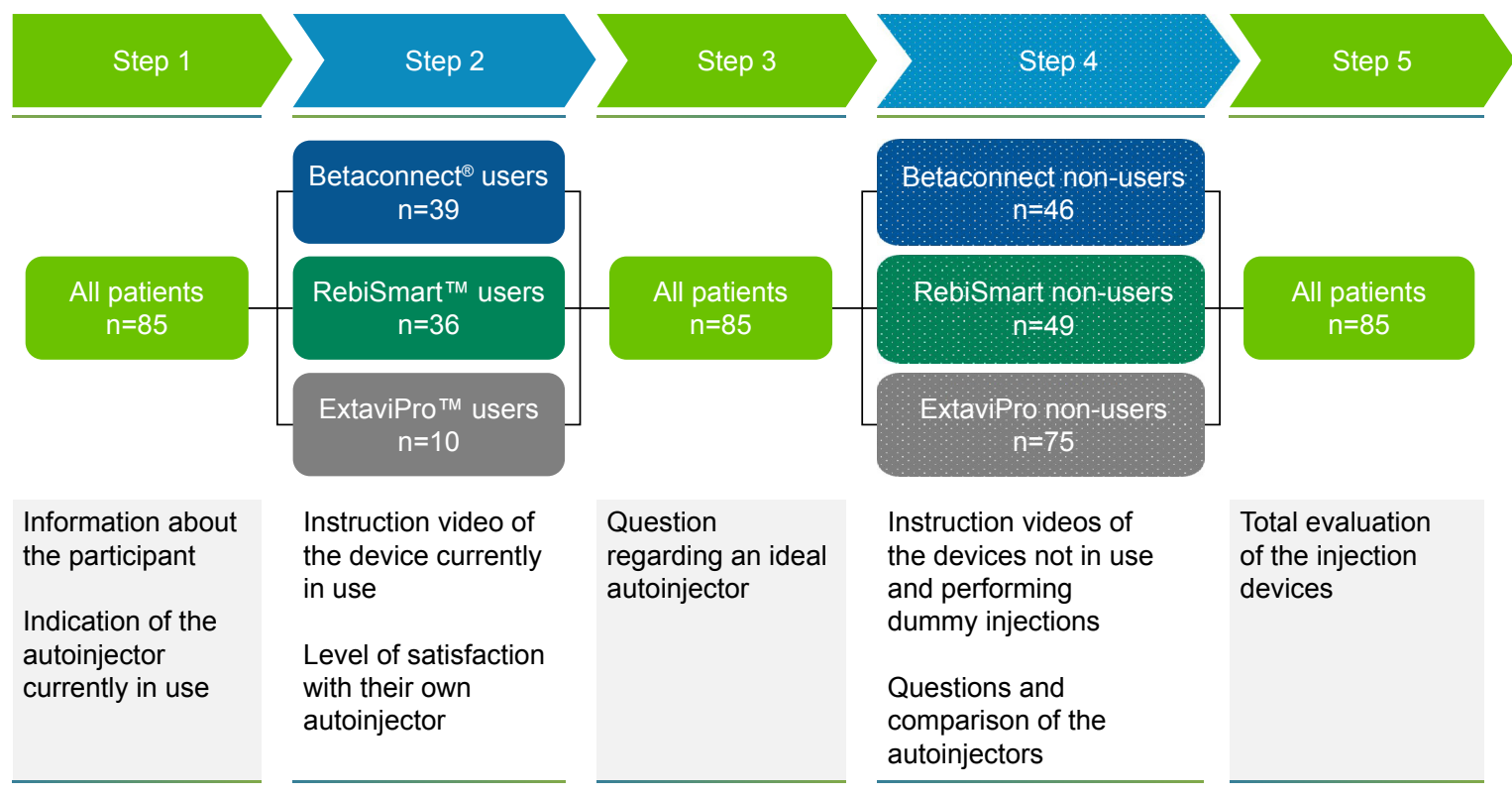

Figure I Flowchart of the survey.

Note: The diagram displays the progress through the steps of the market survey (instructions and evaluation of device in use, questions regarding ideal device, instructions and evaluation of the two non-used devices, and total evaluation of the devices).

\section{Statistical analysis}

Analyses were primarily of descriptive nature (median, mean, standard deviation). Statistical tests were performed for exploratory purposes and involved Student's $t$-test for independent samples.

\section{Results}

\section{Demographic characteristics}

The majority of the surveyed participants were between 18 and 55 years old (29\% $18-35$ years, $52 \% 36-55$ years, $18 \%$ 56-75 years) and $68 \%$ were female. Among participants, 63 had relapsing-remitting MS, 6 had secondary progressive MS, and 16 patients could not specify their MS type. The participants of the validation group were younger, $80 \%$ were female, and only from one location (Table 1).

Currently, 39 participants used the Betaconnect, 36 the RebiSmart, and 10 the ExtaviPro device. Four of the 85 patients $(5 \%)$ had earlier experiences with one of the autoinjectors assessed in this survey (Betaconnect [ $\mathrm{n}=2]$, RebiSmart $[\mathrm{n}=1]$, and ExtaviPro [n=1]). There were 14 patients in the main group and 2 patients in the validation group who had used other injection devices not part of this market research.

\section{Satisfaction with autoinjector currently in use}

Before presentation of the devices not in use, participants were asked to rate the level of satisfaction with their own device on a scale ( $1=$ not satisfied at all, $10=$ very satisfied $)$.
Table I Demographic characteristics

\begin{tabular}{|c|c|c|}
\hline Characteristic & $\begin{array}{l}\text { Number }(\%) \\
\text { of main analysis } \\
\text { group }(n=85)\end{array}$ & $\begin{array}{l}\text { Number }(\%) \\
\text { of validation } \\
\text { group }(n=\mid 5)\end{array}$ \\
\hline \multicolumn{3}{|l|}{ Gender } \\
\hline Females & $58(68)$ & $12(80)$ \\
\hline Males & $27(32)$ & $3(20)$ \\
\hline \multicolumn{3}{|l|}{ Age (years) } \\
\hline$<18$ & $0(-)$ & $0(-)$ \\
\hline $18-35$ & $25(29)$ & $8(53)$ \\
\hline $36-55$ & $44(52)$ & $6(40)$ \\
\hline $56-75$ & $15(18)$ & I (7) \\
\hline Not specified & $I(1)$ & $0(-)$ \\
\hline \multicolumn{3}{|l|}{ Geographic distribution } \\
\hline Cologne & II (I3) & $15(100)$ \\
\hline Munich & $11(13)$ & $0(-)$ \\
\hline Frankfurt & $17(20)$ & $0(-)$ \\
\hline Berlin & $17(20)$ & $0(-)$ \\
\hline Hamburg & $29(34)$ & $0(-)$ \\
\hline \multicolumn{3}{|c|}{ Current MS medication (autoinjector) } \\
\hline Betaferon ${ }^{\circledR}\left(\right.$ Betaconnect $\left.^{\circledR}\right)$ & $39(46)$ & $7(47)$ \\
\hline $\operatorname{Rebif}^{\circledR}\left(\operatorname{RebiSmart}^{\mathrm{TM}}\right)$ & $36(42)$ & $5(33)$ \\
\hline Extavia $^{\circledR}\left(\right.$ ExtaviPro $\left.^{\mathrm{TM}}\right)$ & $10(12)$ & $3(20)$ \\
\hline \multicolumn{3}{|l|}{ MS type } \\
\hline Relapsing-remitting MS & $63(74)$ & $14(93)$ \\
\hline Secondary progressive MS & $6(7)$ & $0(-)$ \\
\hline Not specified/unaware & $16(19)$ & I (7) \\
\hline \multicolumn{3}{|l|}{ Diagnosis } \\
\hline Before 1990 & $3(4)$ & I (7) \\
\hline $1990-1999$ & $9(11)$ & I (7) \\
\hline $2000-2004$ & $24(28)$ & $0(-)$ \\
\hline $2005-2009$ & $16(19)$ & I (7) \\
\hline $2010-2014$ & $23(27)$ & $6(4 I)$ \\
\hline $2015-2016$ & $9(11)$ & $6(40)$ \\
\hline Not specified/unaware & $\mathrm{I}(\mathrm{I})$ & $0(-)$ \\
\hline
\end{tabular}

Abbreviation: MS, multiple sclerosis. 


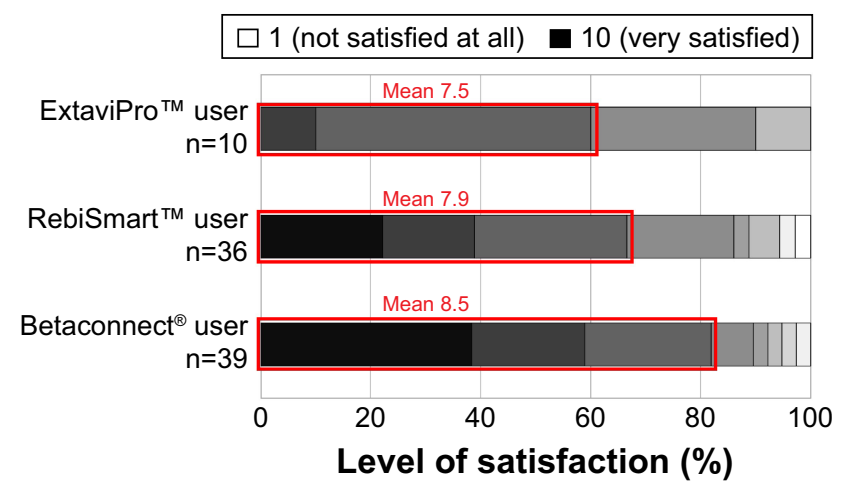

Figure 2 Satisfaction level with device currently in use.

Notes: Participants evaluated their device in use via scale points $(I=$ not satisfied at all, $10=$ very satisfied). The percentage of participants rating with 8-10 points (top three rankings) is highlighted in red (mean values).

There were $82 \%$ of the Betaconnect users who were highly satisfied with their device (8-10 points, mean 8.5), as well as $67 \%$ of the RebiSmart (mean 7.9 ) and $60 \%$ of the ExtaviPro users (mean 7.5) (Figure 2). In the validation group, 3 of 7 Betaconnect users, 3 of 5 RebiSmart users, and 1 of 3 ExtaviPro users indicated high levels of satisfaction with their device.

Betaconnect users $(n=39)$ especially appreciated ease of handling ( $41 \%$ of $n=39)$, reminder for next injection $(31 \%)$, low noise ( $18 \% ; P<0.05$ with respect to RebiSmart users), appealing design (21\%) as well as leads patients clearly through the procedure (18\%), and pain-free injection (18\%). Among RebiSmart users ( $n=36)$, ease of handling (36\%) and ease of operation (28\%) were the most favored features, as well as the design (25\%), leads patients clearly through the procedure $(22 \%)$, and the fact that no syringe is visibly held in the hand $(36 \% ; P<0.05$ with respect to Betaconnect users and ExtaviPro users). ExtaviPro users $(n=10)$ favored that the device is handy $(50 \% ; P<0.05$ with respect to Betaconnect and RebiSmart users), has an appealing design, and easy handling (30\% each). Inconveniences to the disadvantage of ExtaviPro particularly concerned unpleasant noise (30\%; $P<0.05$ with respect to Betaconnect users), size (20\%; $P<0.05$ with respect to Betaconnect users) as well as unhandiness $(20 \% ; P<0.05$ with respect to Betaconnect users), and to the disadvantage of RebiSmart, weight (17\%; $P<0.05$ with respect to Betaconnect users) and problems with the needle ( $17 \% ; P<0.05$ with respect to Betaconnect users). There were $18 \%$ of the Betaconnect patients who complained about the necessity of high pressure/tension when the device is applied to the skin (multiple answers possible).

Most participants in the main analysis group and in the validation group desired improvements of their own device that concern reduction of weight/noise and enhancement of handling (Table 2).

\section{Proposed features/improvements toward ideal device}

As evaluated by the participants, the most important features of an ideal autoinjector comprise general ease of the injection process, uncomplicated preparation of the device before use, possibility of usage without help from others, easy determination of injection start and stop, and ease of pressing button for start of injection (Table 3). The patients of the validation group chose the same characteristics of an ideal autoinjector except for the fact that ease of pressing button for start of injection and intuitive handling of device were more important to them than easy determination of injection start and stop.

\section{Evaluation of the two autoinjectors not in use}

After video instruction and dummy testing of the two devices not in use, participants were asked to evaluate device features of the autoinjectors not in use. The Betaconnect autoinjector received the highest valuation from non-users and the values

Table 2 Most desired improvements of own device proposed by the participants

\begin{tabular}{|c|c|c|c|}
\hline Feature & $\begin{array}{l}\text { Betaconnect }^{\circledR} \text { users } \\
\text { (device } A) n=39\end{array}$ & $\begin{array}{l}\text { RebiSmart }^{\mathrm{TM}} \text { users } \\
\text { (device B) } \mathrm{n}=36\end{array}$ & $\begin{array}{l}\text { ExtaviPro }^{\mathrm{TM}} \text { users } \\
\text { (device C) } \mathrm{n}=10\end{array}$ \\
\hline Handling/application & $26 \%$ & $22 \%$ & $20 \%$ \\
\hline Easier handling & $5 \%$ & $22 \%$ & $20 \%$ \\
\hline $\begin{array}{l}\text { Changes concerning sensor/more sensible } \\
\text { sensor/more reliable skin contact sensor }\end{array}$ & $18 \%$ b & - & - \\
\hline Other & $26 \%$ & $53 \%$ a & $50 \%$ \\
\hline Lighter weight/weight & - & $19 \%$ & - \\
\hline No noise/less noise & $3 \%$ & $3 \%$ & $30 \%$ \\
\hline
\end{tabular}

Notes: $\mathrm{n}=85$, multiple answers possible. ${ }^{\mathrm{a}, \mathrm{b}} \mathrm{P}<0.05$ comparing the respective device with device $\mathrm{A}$, $\mathrm{B}$, or $\mathrm{C}$, respectively. '-' indicates users did not desire changes. 
Table 3 Comparison of ideal device features and availability of these features in the devices ranked by non-users

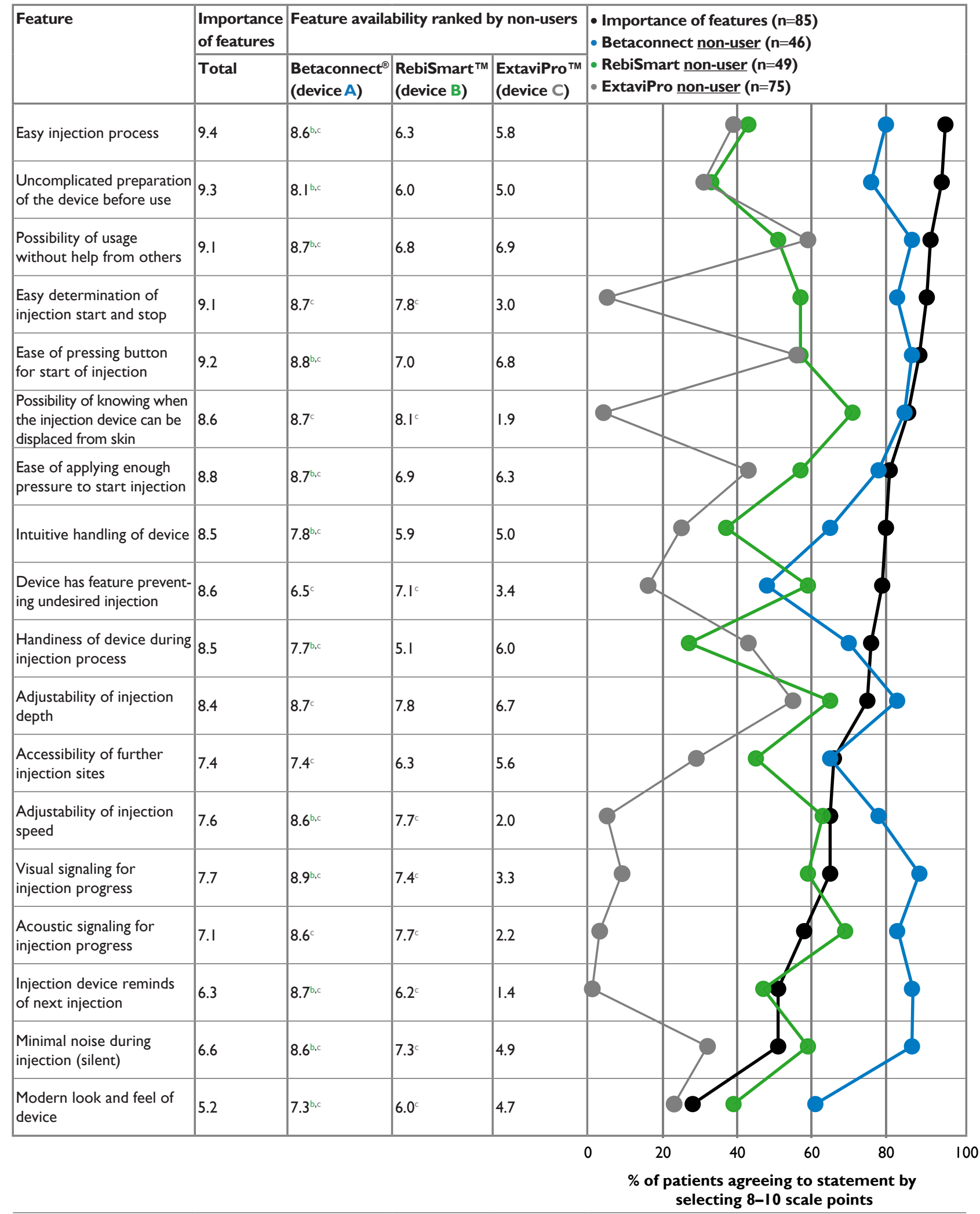

Notes: Patients' top three rankings (8-10 points on rating scale); ${ }^{b, c} p<0.05$ comparing the respective device with device A, B, or C, respectively. For example, regarding "Easy injection process", the Betaconnect (device A) was significantly rated better than the RebiSmart (device B) and the ExtaviPro (device C). 
were closest to those of an ideal injection device. Most appreciated features comprised overall easier handling, start/stop signaling, adjustment of injection speed/depth, reminder function, and visual signaling for injection progress (Figure 3, Table 3). In the validation group, the patients evaluated nearly all features of the three devices higher than patients in the main analysis group. But the ease of pressing button for start of the injection (RebiSmart mean 6.8; Betaconnect mean 8.6) and the minimal noise during injection (RebiSmart mean 7.0; Betaconnect mean 7.9) received a lower valuation for RebiSmart and Betaconnect from the patients of the validation group. The rating for the ease of applying enough pressure for starting injection (mean 6.1) and handiness of RebiSmart during injection process (mean 6.0) as well as the reminder function (mean 7.3) and uncomplicated preparation of Betaconnect before use (mean 6.5) were also lower than in the main analysis group.

In addition, participants evaluated inconveniences of the two devices not in use (percentage of non-users; multiple answers possible): Predominantly, participants disliked the weight of the RebiSmart device $(43 \% ; P<0.05$ with respect to Betaconnect [ $9 \%$ disliked the weight] and ExtaviPro [0\% disliked the weight]), lack of sufficient visual/acoustic functions of the ExtaviPro $(37 \% ; P<0.05$ with respect to Betaconnect and RebiSmart), difficult handling of RebiSmart
(33\%; $P<0.05$ with respect to Betaconnect) and ExtaviPro (24\%; $P<0.05$ with respect to Betaconnect), and unhandiness of RebiSmart ( $24 \% ; P<0.05$ with respect to ExtaviPro), and criticized confusing menu guidance of RebiSmart (31\%; $P<0.05$ with respect to Betaconnect and ExtaviPro) as well as unpleasant noise of ExtaviPro $(21 \% ; P<0.05$ with respect to Betaconnect and RebiSmart). Furthermore, patients disliked complicated assembly (23\%) and excessive release force of the ExtaviPro (17\%) (each $P<0.05$ with respect to Betaconnect and RebiSmart) as well as manual needle retraction of the ExtaviPro device $(21 \% ; P<0.05$ with respect to Betaconnect). Relevant criticism regarding the Betaconnect autoinjector concerned its disposable syringe ( $20 \% ; P<0.05$ with respect to RebiSmart and ExtaviPro). The validation group participants only disliked the weight of RebiSmart (50\%; $P<0.05$ with respect to ExtaviPro) and the unpleasant noise of ExtaviPro $(50 \% ; P<0.05$ with respect to Betaconnect).

\section{Total evaluation of all three injection devices}

After presentation of all devices, participants ranked the injection devices with respect to the preferred autoinjector. On the assumption that their own medication was suitable for all three autoinjectors, $56 \%$ of the participants $(n=48 / 85)$

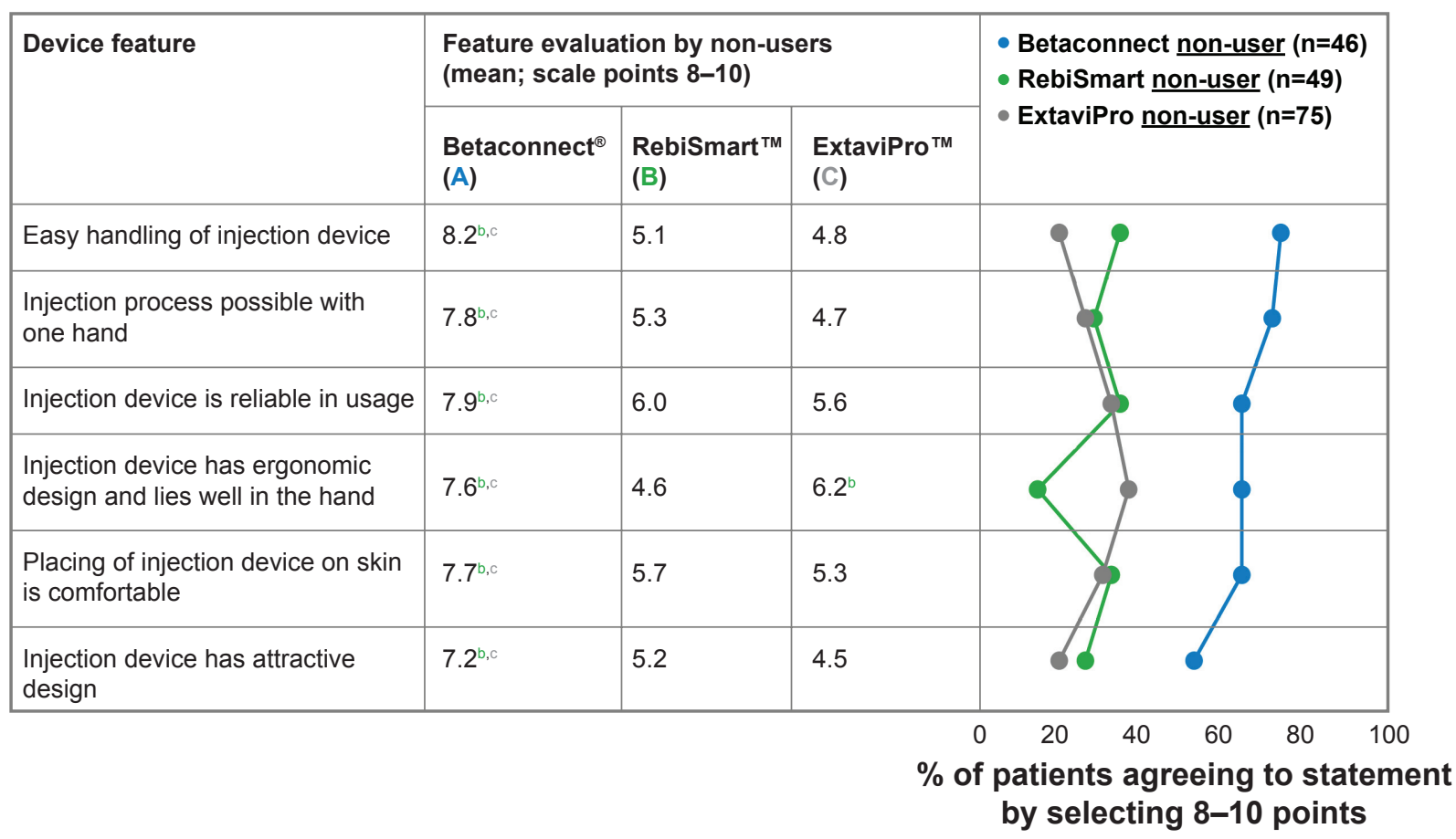

Figure 3 Feature evaluation of the autoinjectors not in use.

Notes: Agreement level of participants with statements regarding features of the devices not in use (non-users) were queried via scale points ( $I=$ not agree at all, $10=$ totally agree). Top three rankings (8-10 points on rating scale, mean values) are listed and significance is indicated (b,c $P<0.05$ comparing the respective device with device A, B, or C, respectively). For example, regarding "Easy handling of the injection device", the Betaconnect (device A) was rated significantly better than the RebiSmart (device B) and the ExtaviPro (device C). The percentage of participants with top-three rankings (8-10 scale points) is illustrated. 


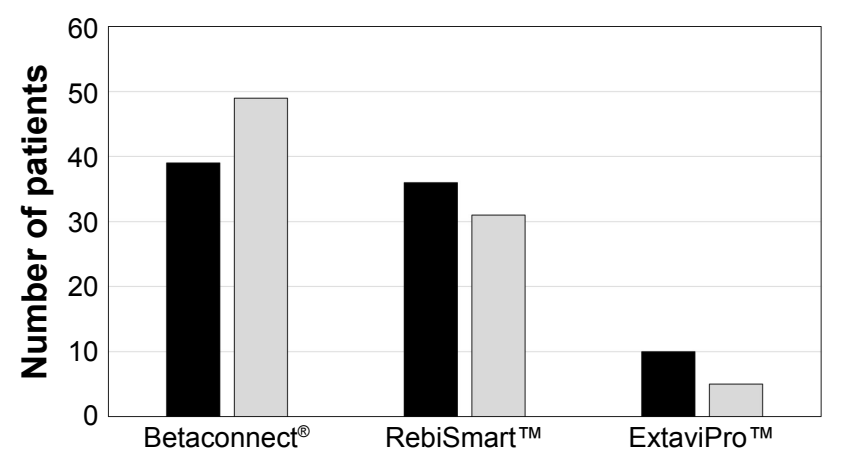

- Injection device before presentation (number of users) $\square$ Preferred injection device after presentation (number of patients)

Figure 4 Final assessment of all three injection devices.

Notes: Participants indicated their autoinjector preference after presentation of all devices (dark; number of patients). Currently used injection devices are depicted for comparison (light; number of users).

chose the Betaconnect, $36 \%$ the RebiSmart ( $\mathrm{n}=31 / 85$ ), and $5 \%$ the ExtaviPro device $(n=4 / 85) ; 2 \%$ did not answer $(\mathrm{n}=2 / 85)$. Thus, after device presentation, in total 9 Betaconnect non-users in the main analysis group would now prefer switching from RebiSmart (total loss; $\mathrm{n}=5$ ) and ExtaviPro (total loss; $n=6$ ) to this autoinjector (Figure 4), provided their own medication was suitable for the Betaconnect device. A total of 8 patients of the validation group would prefer the Betaconnect, 2 patients the RebiSmart, and 5 patients the ExtaviPro autoinjector.

\section{Discussion}

Use of autoinjection devices is well-established in selfadministered therapies (e.g., s.c. interferon beta formulations) and might help contribute to improved adherence, which is a hallmark for treatment success. ${ }^{2,12}$ A variety of surveys has evaluated patient satisfaction with electronic and mechanical autoinjectors as well as manual injection to date. ${ }^{8-10,14-19}$ In our survey, we queried patient needs and preferences with respect to current electronic (Betaconnect, RebiSmart) and mechanical (ExtaviPro) autoinjectors. These are autoinjectors typically available in Europe for s.c. interferon beta formulations. To our knowledge, a side-by-side evaluation of the available autoinjectors has not been performed before. In this survey, it is the first time that participants received video presentation of all evaluated devices and the possibility to dummy-inject with the two devices not used by the patient to enable objective evaluation of the device in current use and the comparator devices.

Initially, survey participants were largely satisfied with their current device in use - with slightly more satisfied Betaconnect users. These data were received before video presentation and dummy-testing of the two devices not in use. In addition, only $5 \%$ of the participants had prior experiences with one of the other two autoinjectors in this market survey. Thus, indicated satisfaction levels were mainly independent of function and features provided by the devices not in use, and participants at this time were not aware of advantages or disadvantages of their device in comparison to the other two devices.

According to our findings, the ideal injection device leads patients through the process with sufficient and clear menu guidance, accompanied by visual and acoustic signaling. Easy assembly of the device, handiness (rendering patients independent from the help of others), adjustable injection settings, and no presence of disturbing noise or movement are important features as well as a hidden needle without necessity of manual retraction. Further details concern the prevention of disposable products, presence of an easily rechargeable battery, and a reminder function for upcoming injections. Some of these aspects have also been rated important in other patient surveys. ${ }^{5,6,8,10,14,15}$ Besides convenienceassociated factors, some features might have direct impact on treatment adherence: since forgetfulness as well as needle-phobia are important obstacles to adherence, ${ }^{3,10}$ a reminder of upcoming injections and a comfortable injection process (without manual needle retraction) could generally be an advantage.

Among the tested devices, the Betaconnect was rated significantly higher by non-users with respect to most queried features and closest to the participants' ideal, which is in line with recent survey findings comparing the Betaconnect device with autoinjectors licensed in the US. Appreciated features (including overall easy injection process, handiness, and adjustability of injection) were similar to our data. ${ }^{15}$ However, a few improvements to the Betaconnect were recommended in our survey (e.g., concerning disposable and visible needle, sensitivity of the contact sensor). RebiSmart and ExtaviPro users mentioned lack of sufficient handiness of their devices. With respect to the mechanical ExtaviPro device, non-users particularly miss those features appreciated regarding the other electronic devices (e.g., sufficient signaling, reminder function).

Considering these findings, it is not surprising that after testing the devices, some participants $(n=9)$ would switch to the Betaconnect, provided their own medication was suitable, and in return, the number of ExtaviPro and RebiSmart users would decline. It is debatable whether these participants were initially already less satisfied with their device in use or if they preferred to switch after discovering the advantages offered by the Betaconnect device. Recent data indicate that patients did not miss certain features in their device before a simulated 
injection with the Betaconnect autoinjector. Presence of these features (e.g., adjustable injection speed, quietness of injection) were rated high by the same patients. ${ }^{15}$

A major issue in the treatment of chronic diseases is adherence. ${ }^{20}$ Treatment support by autoinjectors might help contribute to high medication adherence. A study published in 2011 showed that autoinjectors were baseline predictors of adherence. Patients using an autoinjector at baseline and during the study were more adherent than patients not having used a device. ${ }^{12}$ Furthermore, the use of the autoinjector is positively associated with quality of life. ${ }^{21}$

Addressing adherence is not only a matter of the dosage form, but particularly of perceiving patients' needs in terms of education (necessity of long-term treatment, realistic expectations), ${ }^{2}$ support (support programs, MS nurse, electronic diary with reminder function),,$^{2,21-23}$ and convenience (ideal autoinjection device). Nowadays it has become more and more usual for patients to track health data on their own and share data with health care providers. The Betaconnect device offers the possibility to transfer the injection data into the myBETAapp ${ }^{\circledR}$ for the patient. This assists patients in self-management of their injection therapy. The patient can share his or her injection data through the app with the health care providers. The RebiSmart also allows data sharing between patient and health care professionals. Mechanical autoinjectors like the ExtaviPro lack the technology to save and share injection-related data.

Despite oral therapies in MS, injectable treatment options like the beta interferons for s.c. administration, have an important value in the MS therapy algorithm and will continue to cover therapeutic needs. S.c. application is not limited to MS therapy, but an application option in many therapeutic areas like oncology. The monoclonal antibodies rituximab and trastuzumab used to be delivered by the intravenous route, but later s.c. formulations were developed to improve patients' comfort. Recent studies have demonstrated that s.c. injections can shorten administration times, offer resource benefits, and improve patient convenience compared to the intravenous application route. Efficacy and tolerability did not differ from intravenous formulations. ${ }^{24,25}$

Therefore, with a view to the future, additional innovations of the injection devices might be important to improve patient satisfaction with injection therapy in MS and other therapeutic areas.

\section{Conclusion}

Major hallmarks in the management of chronic diseases such as MS are patient convenience and treatment adherence.
In the case of self-administered therapies, these issues are particularly addressed by development and advancement of innovative autoinjection devices which meet patients' needs. In our survey, the Betaconnect device was the most preferred autoinjector and rated closest to an ideal device. Thus, the Betaconnect might contribute to patient convenience and subsequently to improved treatment adherence. These results need to be confirmed in further studies.

\section{Acknowledgments}

The survey was funded by Bayer Vital GmbH, the manufacturer of Betaconnect. Medical writing services from Dr Carmen Koch, employee of KW medipoint, were also funded by Bayer Vital GmbH. The results based on the entire cohort $(n=100)$ were presented at the ISPOR 19th Annual European Congress in 2016 as a poster presentation with interim findings. The poster's abstract was published in "Poster Abstracts" in Value in Health.

\section{Author contributions}

VL revised the manuscript for intellectual content. All authors contributed toward data analysis, drafting and revising the paper and agree to be accountable for all aspects of the work.

\section{Disclosure}

VL is the Head of Department of Neurology, Cologne General Hospitals, University of Cologne, Cologne, Germany. VL has received speaker's honoraria, financial research support or consultancy fees from Antisence, Allergan, Almirall, Bayer, Biogen, Bionorica, Genzyme, Novartis, Roche, Sanofi, and Teva. VL received honoraria for a workshop to evaluate the results and to interpret the data of the market research. TS, JR, XM, AK, and IW are salaried employees of Bayer Vital GmbH. BM is a salaried employee of IFAK Institute $\mathrm{GmbH} \& \mathrm{Co}$. KG, Taunusstein, Germany. The authors report no other conflicts of interest in this work.

\section{References}

1. Bayas A. Improving adherence to injectable disease-modifying drugs in multiple sclerosis. Expert Opin Drug Deliv. 2013;10(3):285-287.

2. Lugaresi A, Rottoli MR, Patti F. Fostering adherence to injectable disease-modifying therapies in multiple sclerosis. Expert Rev Neurother. 2014;14(9):1029-1042.

3. Treadaway K, Cutter G, Salter A, et al. Factors that influence adherence with disease-modifying therapy in MS. J Neurol. 2009;256(4):568-576.

4. Wingerchuk DM, Carter JL. Multiple sclerosis: current and emerging disease-modifying therapies and treatment strategies. Mayo Clin Proc. 2014;89(2):225-240.

5. Bayas A, Japp G, Fulda U, Kallmann BA. Injection devices in MS therapy: survey on neurologists, MS-nurses and patients. Nervenheilkunde. 2010;29:57-62. 
6. D'Arcy C, Thomas D, Stoneman D, Parkes L. Patient assessment of an electronic device for subcutaneous self-injection of interferon beta-1a for multiple sclerosis: an observational study in the UK and Ireland. Patient Prefer Adherence. 2012;6:55-61.

7. de Sa J, Urbano G, Reis L. Assessment of new application system in Portuguese patients with relapsing-remitting multiple sclerosis. Curr Med Res Opin. 2010;26(9):2237-2242.

8. Devonshire V, Arbizu T, Borre B, et al. Patient-rated suitability of a novel electronic device for self-injection of subcutaneous interferon beta-1a in relapsing multiple sclerosis: an international, single-arm, multicentre, Phase IIIb study. BMC Neurol. 2010;10:28.

9. Phillips JT, Fox E, Grainger W, Tuccillo D, Liu S, Deykin A. An openlabel, multicenter study to evaluate the safe and effective use of the single-use autoinjector with an Avonex ${ }^{\circledR}$ prefilled syringe in multiple sclerosis subjects. BMC Neurol. 2011;11:126.

10. Verdun di Cantogno E, Russell S, Snow T. Understanding and meeting injection device needs in multiple sclerosis: a survey of patient attitudes and practices. Patient Prefer Adherence. 2011;5:173-180.

11. Brochet B, Lemaire G, Beddiaf A, et l'Epicure Study G. Réduction des réactions cutanées aux points d'injection avec deux auto-injecteurs chez des patients ayant une sclérose en plaques rémittente débutant un traitement par interféron bêta-1b : étude randomisée en cross-over. [Reduction of injection site reactions in multiple sclerosis (MS) patients newly started on interferon beta $1 \mathrm{~b}$ therapy with two different devices]. Rev Neurol (Paris). 2006;162(6-7):735-740. French.

12. Pozzilli C, Schweikert B, Ecari U, Oentrich W; BetaPlus Study group. Supportive strategies to improve adherence to IFN beta-1b in multiple sclerosis - results of the betaPlus observational cohort study. J Neurol Sci. 2011;307(1-2):120-126.

13. Bayas A, Ouallet JC, Kallmann B, et al. Adherence to, and effectiveness of, subcutaneous interferon beta-1a administered by RebiSmart $\mathbb{R}$ in patients with relapsing multiple sclerosis: results of the 1-year, observational SMART study. Expert Opin Drug Deliv. 2015;12(8): 1239-1250.

14. Weller I, Saake A, Schreiner T, Vogelreuter J, Petroff N. Patient satisfaction with the BETACONNECT ${ }^{\mathrm{TM}}$ autoinjector for interferon beta-1b. Patient Prefer Adherence. 2015;9:951-959.
15. Barone DA, Singer BA, Merkov L, Rametta M, Suarez G. Survey of US patients with multiple sclerosis: comparison of the new electronic interferon beta-1b autoinjector (BETACONNECT ${ }^{\mathrm{TM}}$ ) with mechanical autoinjectors. Neurol Ther. 2016;5(2):155-167.

16. Ziemssen T, Sylvester L, Rametta M, Ross AP. Patient satisfaction with the new interferon beta-1b autoinjector (BETACONNECT ${ }^{\mathrm{TM}}$ ). Neurol Ther. 2015;4(2):125-136.

17. Singer B, Wray S, Miller T, et al. Patient-rated ease of use and functional reliability of an electronic autoinjector for self-injection of subcutaneous interferon beta-1a for relapsing multiple sclerosis. Mult Scler Relat Disord. 2012;1(2):87-94.

18. Hupperts R, Becker V, Friedrich J, et al. Multiple sclerosis patients treated with intramuscular IFN-beta-1a autoinjector in a real-world setting: prospective evaluation of treatment persistence, adherence, quality of life and satisfaction. Expert Opin Drug Deliv. 2015;12(1):15-25.

19. Thakur K, Manuel L, Tomlinson M. Autoinjectors for administration of interferon beta-1b in multiple sclerosis: patient preferences and the ExtaviPro $^{\text {TM }} 30 \mathrm{G}$ and Betacomfort ${ }^{\circledR}$ devices. Pragmat Obs Res. 2013; 4:19-26.

20. WHO. Adherence to long-term therapies - Evidence for action. Geneva: World Health Organization; 2003.

21. Pozzilli C, Schweikert B, Ecari U, Oentrich W, Bugge JP. Quality of life and depression in multiple sclerosis patients: longitudinal results of the BetaPlus study. J Neurol. 2012;259(11):2319-2328.

22. Kohlmann T, Wang C, Lipinski J, et al. The impact of a patient support program for multiple sclerosis on patient satisfaction and subjective health status. J Neurosci Nurs. 2013;45(3):E3-E14.

23. Zettl UK, Bauer-Steinhusen U, Glaser T, et al. Adherence to long-term interferon beta-1b injection therapy in patients with multiple sclerosis using an electronic diary. Adv Ther. 2016;33(5):834-847.

24. Assouline S, Buccheri V, Delmer A, et al. Pharmacokinetics and safety of subcutaneous rituximab plus fludarabine and cyclophosphamide for patients with chronic lymphocytic leukaemia. Br J Clin Pharmacol. 2015;80(5):1001-1009.

25. Shpilberg O, Jackisch C. Subcutaneous administration of rituximab (MabThera) and trastuzumab (Herceptin) using hyaluronidase. $\mathrm{Br} J$ Cancer. 2013;109(6):1556-1561. 


\section{Supplementary material}

Table SI Questionnaire used for the structured face-to-face interviews

\begin{tabular}{|c|c|c|c|}
\hline & $\begin{array}{l}\text { Answer by } \\
\text { marking }\end{array}$ & $\begin{array}{l}\text { Answer by rating } \\
\text { I (worst) - } 10 \text { (best) }\end{array}$ & $\begin{array}{l}\text { Open } \\
\text { question }\end{array}$ \\
\hline \multicolumn{4}{|l|}{ Step I: Indication of the autoinjector currently in use } \\
\hline I. Which autoinjector do you currently use? & $x$ & & \\
\hline \multicolumn{4}{|l|}{ Step 2: Instruction videos of the device currently in use and questions about own device } \\
\hline $\begin{array}{l}\text { 2. Please show on a scale from I (not satisfied at all) to } 10 \text { (very satisfied), how satisfied you } \\
\text { are in general with your current injection device for your MS therapy. }\end{array}$ & & $\mathrm{x}$ & \\
\hline 3. Why did you choose the value $x$ on the scale? & & & $x$ \\
\hline 4. When thinking of your injection device, what do you like most? & & & $x$ \\
\hline 5. Which feature of your device do you not like? & & & $\mathrm{x}$ \\
\hline 6. Did you use other devices before? If so, which? & & & $x$ \\
\hline 7. In comparison to your current device, did you like the former one more, less or the same? & $x$ & & \\
\hline 8. (If better) Why was the former one better? & & & $x$ \\
\hline 9. (If worse) Why was the former one worse? & & & $x$ \\
\hline 10. What would you like to change regarding your current injection device if you could? & & & $x$ \\
\hline $\begin{array}{l}\text { II. Please show on a scale from I (not agree at all) to I0 (totally agree), how much you } \\
\text { agree/disagree with all of the following statements regarding your current MS therapy and } \\
\text { the related device. }\end{array}$ & & $\mathrm{x}$ & \\
\hline \multicolumn{4}{|l|}{ Step 3: Question regarding an ideal injection device } \\
\hline $\begin{array}{l}\text { 12. Please show on a scale from I (not important at all) to } 10 \text { (most important), how } \\
\text { important each of the following features is for an ideal injection device for MS therapy. } \\
\text { Please choose } 10 \text { only for one feature. }\end{array}$ & & $\mathrm{x}$ & \\
\hline \multicolumn{4}{|c|}{$\begin{array}{l}\text { Step 4: Questions about the two devices not in use after instruction video presentation and performing dummy injections. Comparison of the } \\
\text { autoinjectors }\end{array}$} \\
\hline $\begin{array}{l}\text { 13. Please now compare the two injection devices with each other with the help of a feature } \\
\text { list and show us on a scale from I (not agree at all) to I0 (totally agree), how much you } \\
\text { agree/disagree with respect to each injection device. }\end{array}$ & & $\mathrm{x}$ & \\
\hline $\begin{array}{l}\text { 14. Please show on a scale from I (not at all) to } 10 \text { (best), which injection device fulfills the } \\
\text { following properties. }\end{array}$ & & $x$ & \\
\hline \multicolumn{4}{|l|}{$\begin{array}{l}X X \text { with the device } X Y \text { (Table with injection device } X Y \text { )? Scale from I (not agree at all) to } \\
\text { I0 (totally agree). }\end{array}$} \\
\hline \multicolumn{4}{|l|}{$\begin{array}{l}\text { XX with the device XZ (Table with injection device XZ)? Scale from I (not agree at all) to } \\
10 \text { (totally agree). }\end{array}$} \\
\hline $\begin{array}{l}\text { 17. Which features of the injection device } \mathrm{XY} \text { do you like most in comparison to your } \\
\text { current device? }\end{array}$ & & & $x$ \\
\hline 18. Which features do you like the least? & & & $x$ \\
\hline $\begin{array}{l}\text { 19. Which features of the injection device } X Z \text { do you like most in comparison to your } \\
\text { current device? }\end{array}$ & & & $x$ \\
\hline 20. Which features do you like the least? & & & $x$ \\
\hline \multicolumn{4}{|l|}{ Step 5: Total evaluation of the injection devices } \\
\hline $\begin{array}{l}\text { 21. On the assumption that your own medication is suitable for all } 3 \text { autoinjectors: How do } \\
\text { you rate the injection device in comparison? Please make a sequence from I to } 3 \text {. }\end{array}$ & $x$ & & \\
\hline $\begin{array}{l}\text { 22. If you could freely choose, which injection device would you prefer to use - provided your } \\
\text { own medication is suitable for all } 3 \text { autoinjectors? }\end{array}$ & $x$ & & \\
\hline
\end{tabular}

Notes: $X X, X Y$ and $X Z$ were dependent on which device was used by the respective patient: $X X$ was the device in current use. $X Y$ and $X Z$ were the two devices not in use. For example, if $X X$ is the Betaconnect ${ }^{\circledR}$, then $X Y$ and $X Z$ are the RebiSmart ${ }^{\mathrm{TM}}$ and the ExtaviPro ${ }^{\mathrm{TM}}$, respectively.

Abbreviation: MS, multiple sclerosis.

Patient Preference and Adherence

\section{Dovepress}

\section{Publish your work in this journal}

Patient Preference and Adherence is an international, peer-reviewed, open access journal that focuses on the growing importance of patient preference and adherence throughout the therapeutic continuum. Patient satisfaction, acceptability, quality of life, compliance, persistence and their role in developing new therapeutic modalities and compounds to optimize clinical outcomes for existing disease states are major areas of interest for the journal. This journal has been accepted for indexing on PubMed Central. The manuscript management system is completely online and includes a very quick and fair peer-review system, which is all easy to use. Visit http://www. dovepress.com/testimonials.php to read real quotes from published authors. 